\title{
Aspectos reprodutivos do caranguejo guaia, Menippe nodifrons Stimpson (Crustacea, Decapoda, Xanthidae) da Baía de Sepetiba, Rio de Janeiro, Brasil
}

\author{
Lidia Miyako Yoshii Oshiro ${ }^{1}$
}

\begin{abstract}
Reproductive aspects of the guaia stone crab, Menippe nodifrons Stimpson (Crustacea Decapoda, Xanthidae) at the Sepetiba Bay, Rio de Janeiro, Brazil. The objective of this work was to get some knowledge about the Guaia stone crab reproduction. The sampling was monthly obtained in the intertidal zone at the Ibicuí Rock Beach. The 638 crabs were collected from August, 1995 to March, 1997. In this total amount 293 were males and 345 ( 41 ovigerous crabs) were female crabs. Biometrical data informing the total width and length were taken, and gonadal stage was checked macroscopically. The total male width range was between 7.9 to 67.1 $\mathrm{mm}$, while in the female crabs it was between 4.4 to $79.3 \mathrm{~mm}$. The female ones were bigger than the male ones. The ovigerous female crabs were found mainly on Spring and Summer and it probably indicates the reproduction season. The carapace width range of the ovigerous female crabs was about 38.0 and $77.0 \mathrm{~mm}$. The individual fecundity was determined on the number of eggs laid, which were dissociated by means of sodium hipoclorito. The number of eggs laid was about 12,800 and 212,000, according to the female size and the average number of the eggs was 98,800 . They were round in shape and their size varied between 0.31 and $0.44 \mathrm{~mm}$. Their average size was $0.37 \mathrm{~mm}$. The five female gonadal stages were determined by the color and the width of the gonads. The estimated mean size of first sexual maturity was $37.8 \mathrm{~mm}$ carapace width for female.
\end{abstract}

KEY WORDS. Decapoda, Xanthidae, Menippe nodifrons, reproduction, stone crab, Sepetiba Bay

Menippe nodifrons Stimpson, 1859 se distribui no Atlântico ocidental, da Flórida, Golfo do México, América Central, Antilhas, norte da América do Sul, Guianas e Brasil (do Maranhão até Santa Catarina), e no Atlântico oriental, de Cabo Verde até Angola (MELo 1996). Provavelmente, devido ao seu tamanho menor em relação às espécies exploradas comercialmente, o seu aproveitamento para o consumo humano tem sido menos freqüente. Mas, esporadicamente pode ser encontrado em pratos típicos em restaurantes e oferecido vivo aos turistas, em regiões litorâneas. Nas praias rochosas onde ocorre é comum verificar pescadores amadores e turistas atraindo-o com iscas e capturando-o manualmente, para o consumo caseiro.

No Sul da Flórida, Menippe mercenaria (Say) é explorado comercialmente, onde apenas a quela maior é coletada e os animais são devolvidos ao mar; e quando a quela é regenerada, novamente fazem parte do estoque pesqueiro. Além disso,

1) Estação de Biologia Marinha, Posto de Aqüicultura, Universidade Federal Rural do Rio de Janeiro. Antiga Rodovia Rio-São Paulo, Km 47, 23851-970 Seropédica, Rio de Janeiro, Brasil. 
nessa região se encontram estabelecidos: a estação de defeso, proibindo a pesca das fêmeas ovígeras durante a época de reprodução; e o tamanho que permite os caranguejos reproduzirem pelo menos uma vez, antes de entrarem para o estoque pesqueiro (EHRHARDT 1990). Outra espécie que também possui potencial para pesca comercial é Menippe adina Williams \& Felder, 1986, que ocorre na região nordeste do Golfo do México. Essas espécies vem sendo estudadas intensamente sobre diversos aspectos da biologia, em diversos locais: BERT et al. (1978), M. mercenaria no sudoeste da Flórida; CALDwell (1992), M. mercenaria na Carolina do Sul; LANDRY (1992), M. adina, na Baía de Galveston, no Texas; STUCK \& PERRY (1992), M. adina nas águas costeiras do Mississipi; BALtz \& Horst (1992) M. adina na Baía de Barataria, em Louisiana; WILBER $(1989,1992)$, M. mercenaria e M. adina e dos seus híbridos, no Golfo do México.

Informações sobre $M$. nodifrons, vulgarmente chamada na região de Guaiá, são escassas, havendo apenas registros de sua ocorrência em trabalhos de levantamento da fauna de crustáceos decápodos (OliveIRA 1940; CoELHO 1966; CoELHO \& RAMOS 1972; CoElHo \& RAMOS-PoRTO 1980; FAUSTO-FILHO 1978; SAMPAIO \& FAUSTO-FilHo 1984; Moreira et al. 1988; ABELE \& Kim 1989; Fronsozo et al. 1992). Estudos específicos foram realizados sobre o desenvolvimento larval por SCOTTO (1979) e do juvenil por Fronsozo et al. (1988). Portanto, muito pouco se conhece no Brasil acerca da sua biologia e ecologia, havendo necessidade de ampliar informações, face à sua ampla distribuição, abundância, além de ser uma espécie que vem sendo capturada para ser comercializada, embora com pouca freqüência.

Este trabalho teve como objetivo contribuir para o conhecimento de aspectos reprodutivos de M. nodifrons na Baía de Sepetiba, Rio de Janeiro.

\section{MATERIAL E MÉTODOS}

Os caranguejos foram capturados mensalmente durante o período de agosto de 1995 a março de 1997, na praia rochosa de Ibicuí, município de Mangaratiba, na Baía de Sepetiba, estado do Rio de Janeiro (Fig. 1). Durante o ano de 1995, a coleta dos caranguejos foi efetuada manualmente, com o auxílio de luvas e pinças, durante a maré baixa, retirando-se os animais após o deslocamento das pedras, na região média e inferior do mesolitoral. A partir de fevereiro de 1996, os indivíduos foram coletados durante a maré baixa, entre a região inferior do mesolitoral e na região superior do infralitoral, atraindo-os com isca (peixes) e coletando-os manualmente.

O material coletado foi etiquetado e guardado no freezer até o processamento. Após o descongelamento, o processamento consistiu na determinação de sexo, medição da largura e comprimento total e pesagem do animal. As fêmeas foram dissecadas e examinadas macroscopicamente, de acordo com a coloração e a espessura das gônadas. Os estádios de desenvolvimento gonadal foram estabelecidos de acordo com aqueles utilizados para M. mercenaria (NoE 1967 apud CALDWELL 1992), embora $M$. nodifrons tivesse apresentado algumas diferenças em relação à coloração das gônadas.

Nas fêmeas ovígeras, os pleópodos com a massa de ovos foram retirados, e os ovos foram dissociados utilizando-se a solução $100 \%$ de hipoclorito de sódio, durante alguns segundos, e a seguir lavando-os em água corrente. Os ovos foram 
colocados num béquer completando-se o volume a $200 \mathrm{ml}$, a amostra foi homogeneizada e tomadas três sub-amostras de $1 \mathrm{ml}$, e contados o número de ovos. Através da média das sub-amostras, estimou-se o número total de ovos. Os ovos foram contados utilizando-se uma câmara de contagem e um contador manual, sob um microscópio estereoscópico.

O diâmetro dos ovos foi efetuada através de uma ocular micrométrica do microscópio estereoscópico, aumento de 25 vezes, medindo-se aleatoriamente 20 ovos de cada fêmea ovígera, obtendo-se o tamanho médio dos ovos.

O tamanho mínimo de primeira maturação gonadal foi estimado segundo VAZzoLER (1981), considerando-se fêmeas adultas de acordo com o desenvolvimento gonadal e o volume das espermatecas.

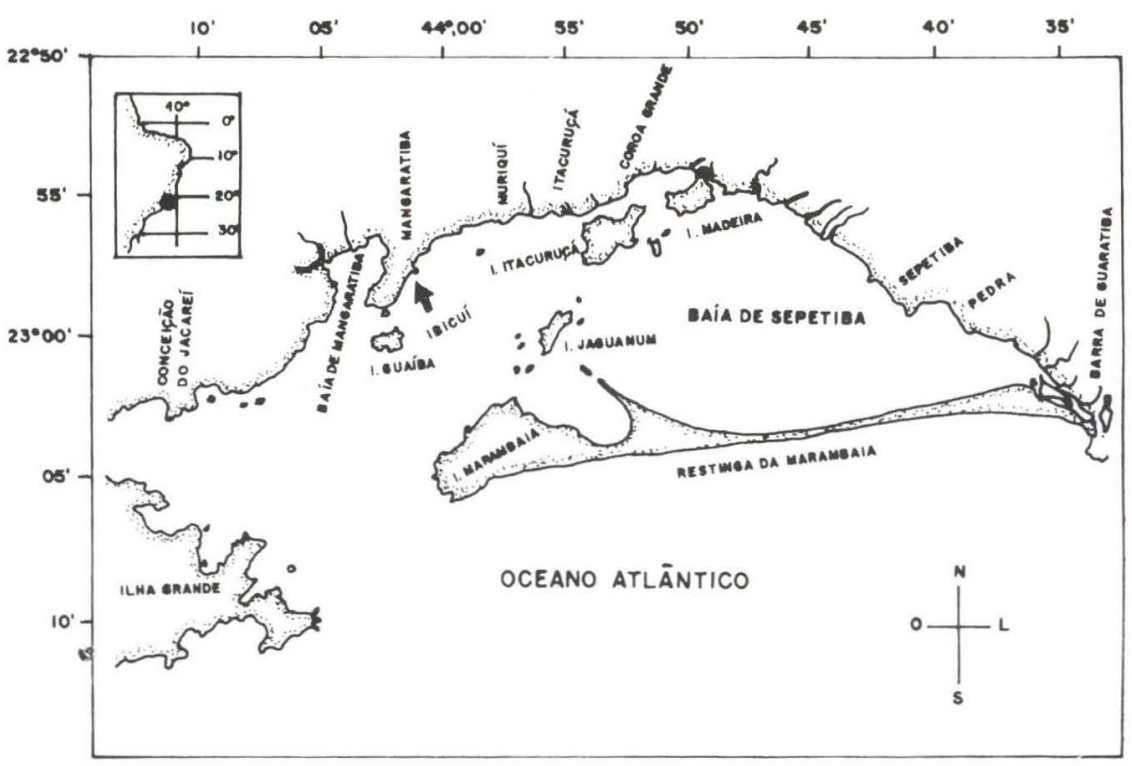

Fig. 1. Localização do ponto de amostragem de Menippe nodifrons, Praia de Ibicui, Mangaratiba, Rio de Janeiro.

\section{RESULTADOS E DISCUSSÃO}

Foram capturados um total de 638 indivíduos das quais, $46 \%$ machos e $54 \%$ fềmeas. A razão sexual média foi de 1:1,2 (macho: fềmea), havendo uma diferença significativa ( $\#=0,05$ com predominância das fêmeas, constatado através do teste do $\mathrm{X}^{2}$. Entretanto, verifica-se que houve variação no número de indivíduos machos em relação às fêmeas durante o período de estudo, observando-se nítidamente que durante o outono (março, abril e maio) houve uma predominância de machos e no verão (dezembro, janeiro e fevereiro) de fêmeas (Fig. 2).

A razão sexual no verão foi de 1,00:2,05; no outono de 1,58: 1,00; no inverno (junho, julho e agosto) de 1,00: 1,00 e na primavera (setembro, outubro e novembro) de 1,00: 1,04 (macho: fêmea). Esta variação sazonal da razão sexual foi verificado 
também para M. mercenaria e $M$. adina, onde os autores alegam a predominância dos machos na época do acasalamento, quando a fêmea realiza a muda, ou das fêmeas na época reprodutiva, no verão (BERT et al. 1986; CALDWELL 1992; LANDRY 1992; STUCK \& PERRY 1992; WiLBER 1992). A razão sexual média encontrada no presente trabalho foi muito semelhante àquela encontrado por CALDWELL (1992), de 1,00: 1,26 (macho: fềmea), para M. adina, na Carolina do Sul.
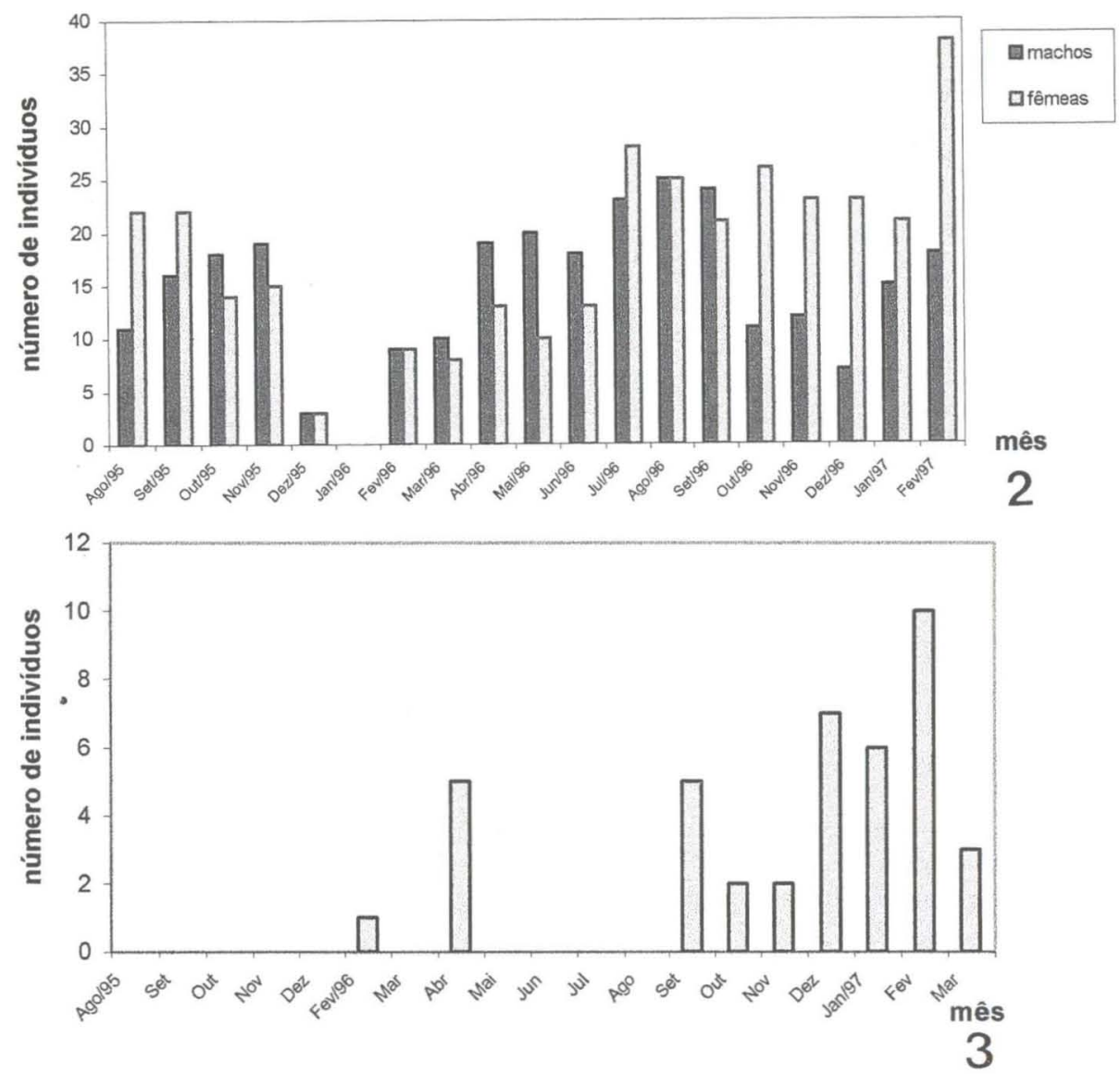

Figs 2-3. Menippe nodifrons coletados durante o período de agosto de 1995 a março de 1997 na praia de Ibicuí, Mangaratiba, Rio de Janeiro. (2) Freqüência de ocorrência; (3) freqüência mensal do número de fêmeas ovígeras.

A análise das 41 fêmeas ovígeras indica um longo período de reprodução estendendo-se entre os meses de primavera até meados do outono, com maior predominância durante o verão (Fig. 3). A ausência de fêmeas ovígeras durante o período de 1995, provavelmente, foi devido à metodologia empregada na coleta, quando os exemplares foram capturados em locais mais rasos, onde foram abun- 
dantes os indivíduos de menor tamanho. Os indivíduos maiores e maduros foram encontrados na região inferior do mesolitoral e superior do infralitoral. WILBER (1992), também verificou a presença de indivíduos maiores e de fêmeas ovígeras apenas na região infralitoral, para $M$. mercenaria e $M$. adina.

O longo periodo de reprodução observada para $M$. nodifrons, está de acordo com o registrado por (CALDWELL 1992) para M. mercenaria e por (STUCK \& PERRY 1992) para M. adina.

Através da observação macroscópica das gônadas de fêmeas ovígeras, verificou-se que $M$. nodifrons reproduzem mais de uma vez durante o ano, visto que estas fêmeas com os ovos já em adiantada fase de desenvolvimento, apresentavam as gônadas novamente maduras.

NOE (1967 apud WILBER 1992), nos estudos realizados em M. mercenaria, afirma que fêmeas que acasalam no outono, armazenam espermatozóides nas espermatecas durante o inverno e realizam quatro a seis desovas durante a primavera e verão. CHEUNG (1968), observou fêmeas dessa mesma espécie em experimentos de laboratório, onde estas realizaram mais de dez desovas com ovos viáveis, num mesmo período de intermuda, através de apenas uma copulação.

Macroscópicamente foram identificados cinco estádios: I) imaturos, com as gônadas muito delgadas e transparentes; II) maturação inicial, apresentando as gônadas de coloração amanteigada ou amararelada, com a espessura pouco maior que no estádio anterior; III) maturação avançada, com as gônadas de coloração alaranjada, com maior espessura; IV) maduro, com as gônadas de coloração vermelho vivo, muito espêssas e distribuídas na região anterior da carapaça; e V) desovado, com a gônada de coloração alaranjada clara ou parda e muito flácida. O estádio desovado deve ocorrer muito rapidamente, uma vez que foi verificada em apenas uma fêmea não ovígera e em 11 fêmeas ovígeras. Fêmeas com as gônadas maduras não foram encontradas apenas durante o inverno, demonstrando claramente o período longo de desova desses animais (Fig. 4).

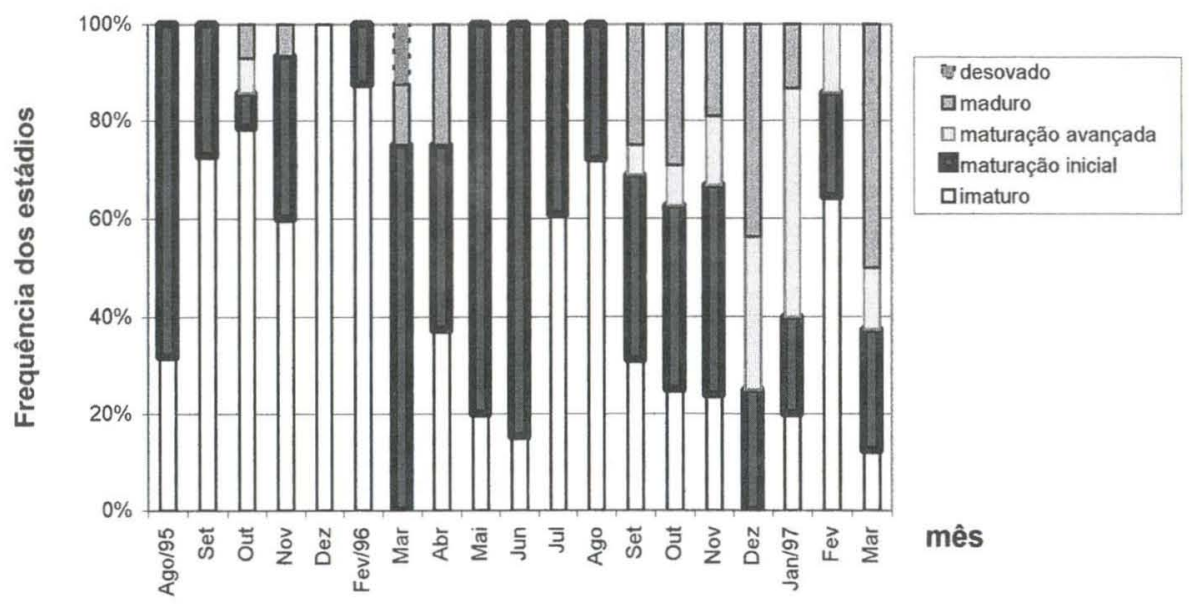

Fig. 4. Distribuição de freqüência dos estádios de maturação gonadal de fêmeas de Menippe nodifrons coletadas de agosto de 1995 a março de 1997 na praia de Ibicui, Mangaratiba, Rio de Janeiro. 

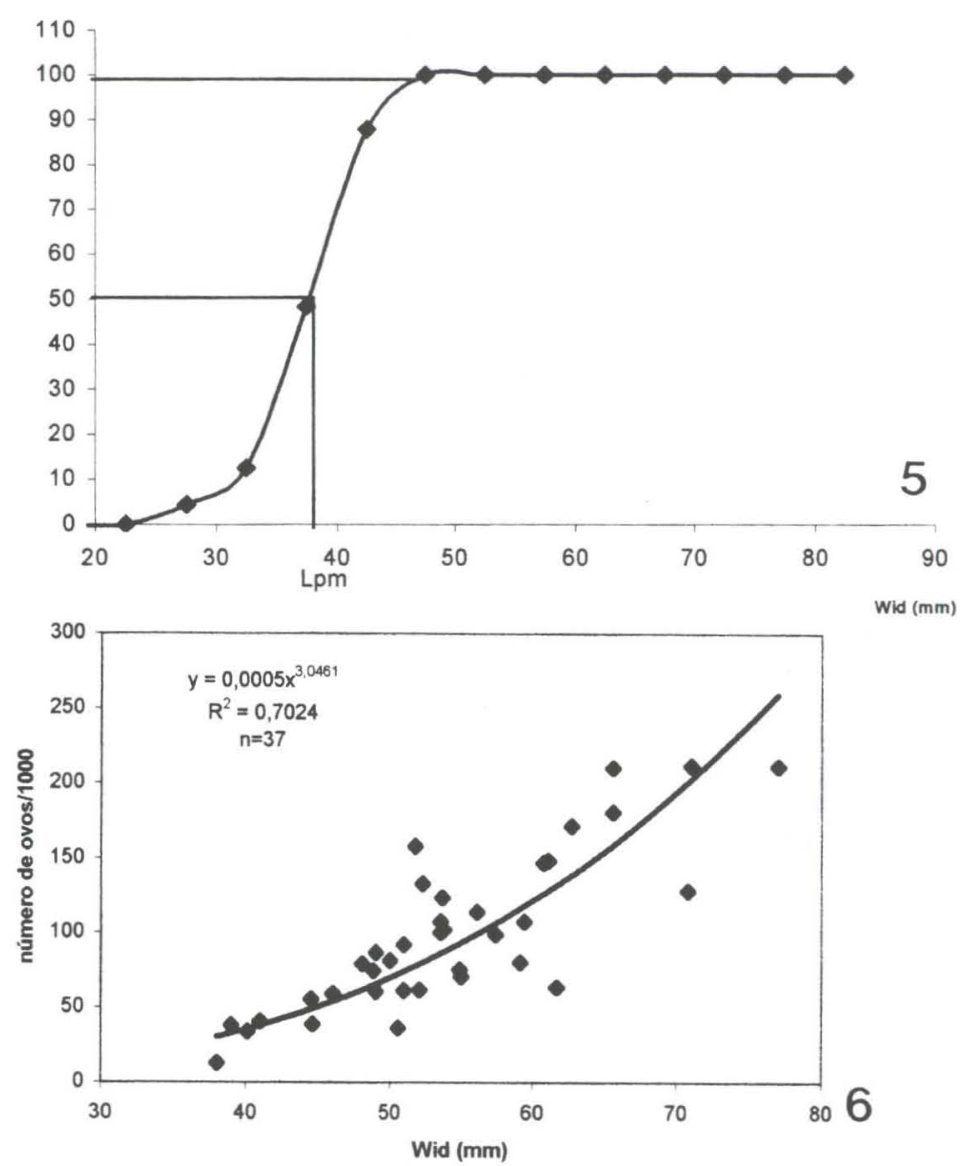

Figs 5-6. Menippe nodifrons coletadas de agosto de 1995 a março de 1997 na praia de Ibicuí, Mangaratiba, Rio de Janeiro. (5) Ditribuição percentual de fêmeas adultas de acordo com a largura da carapaça; (6) relação do número de ovos e largura da carapaça.

O tamanho médio de primeira maturação gonadal das fêmeas foi estimado em 37,8 mm de largura da carapaça (Fig. 5). A menor fêmea ovígera capturada foi de $38,0 \mathrm{~mm}$.

Segundo SulLIVAN (1979), fêmeas de $M$. mercenaria estão sexualmente maduras com $60 \mathrm{~mm}$ de largura da carapaça, baseado na presença de massa de ovos, enquanto WILBER (1992), encontrou a mesma largura para o início da maturação de acordo com a presença de espermatozóides no receptáculo seminal das fêmeas. CALDwell (1992), afirma que na Carolina do Sul as fêmeas de M. mercenaria iniciam a maturação com $55 \mathrm{~mm}$ e os machos com $60 \mathrm{~mm}$.

As fêmeas ovígeras apresentaram a amplitude de largura variando entre 38,0 e $77,0 \mathrm{~mm}$, tendo a fecundidade individual variado de 12.800 a 212.000 ovos, obtendo-se a média individual de 98.800 ovos (Fig. 6). A equação que descreveu a relação entre o número de ovos e a largura da carapaça foi $\mathrm{Y}=0,0005 \cdot \mathrm{X}^{3,0461}$ 
Segundo NoE (1967 apud McConnaughey \& Krantz 1992), fêmeas ovígeras de $M$. mercenaria carregam aproximadamente de 160.000 a 350.000 ovos, estando o número de ovos carregados correlacionado com o tamanho das fêmeas.

O diâmetro dos ovos variou de 0,31 a $0,44 \mathrm{~mm}$, apresentando o tamanho médio de 0,37 mm. RUFFINO et al. (1994), encontraram para Chasmagnathus granulata Dana, 1851 , os ovos variando de 0,29 a $0,50 \mathrm{~mm}$, com diâmetro médio de $0,36 \mathrm{~mm}$ e com desvio padrão de $0,05 \mathrm{~mm}$.

AGRADECIMENTOS. Agradecemos a colaboração do Sr. Casimiro Antonio Alves, Luciano Marques Galdino e estagiários da Estação de Biologia Marinha, Universidade Federal Rural do Rio de Janeiro, que auxiliaram durante o período de coleta dos animais em campo.

\section{REFERÊNCIAS BIBLIOGRÁFICAS}

ABELE, L.G. \& W. Kim. 1989. The decapod Crustaceans of the Panama Canal. Smithson. Contrib. Zool. 482: 1-50.

BALTZ, D.M. \& J.W. HoRsT. 1992. Depth and substrate selection, sex ratio, and size distribution in an unexploited stone crab (Menippe adina) population in Barataria Bay, Louisiana. Fla Mar. Res. Publ. 50: 74-81.

BERT, T.M.; R.E. WARNER \& L.D. KESSLER. 1978. The biology and Florida fishery of the stone crab, Menippe mercenaria (Say), with emphasis on southwest Florida. Fla. Sea Grant Coll. Tech. Pap. 9: 1-82.

Bert, T.M.; J. TILmant; J. Dodrill \& G.E. Davis. 1986. Aspects of the population dynamics and biology of the stone crab (Menippe mercenaria) in Everglades and Biscayne National Parks as determined by trapping. South Fla. Res. Cent. Tech. Rep. SFRC/86-04: 1-77.

Caldwell, M.A. 1992. Aspects of the biology of the stone crab, Menippe mercenaria (Say), from South Carolina, with comments on the South Carolina stone crab fishery. Fla Mar. Res. Publ. 50: 99-106.

Cheung, T.S. 1968. Transmolt retention of sperm in the female stone crab, Menippe mercenaria (Say). Crustaceana 15 (2): 117-120.

Coelho, P.A. 1966. Os crustáceos decápodos de alguns manguezais Pernambucanos e dos Estados vizinhos. Trab. Oceanogr. Univ. Fed. Pernambuco, Recife, 7/8: 71-90.

Coelho, P.A. \& M.A. Ramos. 1972. A constituição e a distribuição da fauna de decápodos do litoral leste da América do Sul entre as latitudes de $5^{\circ} \mathrm{N}$ e $39^{\circ} \mathrm{S}$. Trab. Oceanogr. Univ. Fed. Pernambuco, Recife, 13: 133-236.

Coelho, P.A. \& M.A. Ramos-Porto. 1980. Crustáceos decápodos da costa do Maranhão, Brasil. Bol. Inst. Oceanogr. 29 (2): 135-138.

EHRHARDT, N.M. 1990. Mortality and catchability estimates for the stone crab (Menippe mercenaria) in Everglades National Park. Bull. Mar. Sci. 46 (2): 324-334.

Fausto-Filho, J. 1978. Crustáceos estomatópodos e decápodos do substrato de lama do Nordeste brasileiro. Arq. Ci. Mar 18 (1/2): 63-71.

Fronsozo, A.; M.L. Negreiros-Fransozo \& C.M. Hiyodo. 1988. Développement juvénile de Menippe nodifrons Stimpson, 1859 (Crustacea, 
Decapoda, Xanthidae) au laboratoire. Rev. Hydrobiol. Trop. 21 (4): 297-308. Fransozo, A.; M.L. Negreiros-Fransozo; F.M. Mantelatto, M.A.A. PInHeIro \& S. SANTos. 1992. Composição e distribuição dos Brachyura (Crustacea, Decapoda) do sublitoral não consolidado na enseada da Fortaleza, Ubatuba (SP). Rev. Brasil. Biol. 52 (4): 667-675.

LANDRY JR., A.M. 1992. Characterization and fishery development potential of Galveston Bay, Texas, stone crab (Menippe adina) stocks. Fla Mar. Res. Publ. 50: 67-73.

McConnaughey, R.A. \& G.E. Krantz. 1992. Hatchery production of stone crab, Menippe mercenaria (Say), megalopae. In: Proceedings of a Symposium on Stone Crab (Genus Menippe) Biology and Fisheries. Fla Mar. Res. Publ. 50: 60-66.

MELO, G.A.S. 1996. Manual de identificação dos Brachyura (caranguejos e siris) do litoral brasileiro. São Paulo, Editora Plêiade, 603p.

Moreira, P.S.; A.M. Paiva Filho; C.M. OKidA; J.M.M. Schmiegelow \& R. GIANNINI. 1988. Bioecologia de crustáceos decápodos, braquiúros, no sistema baía-estuário de Santos e São Vicente, SP. 1. Ocorrência e composição. Bol. Inst. Oceanogr. $36(1 / 2)$ : 55-62.

OliveIRA, L.P.H. 1940. Contribuição ao conhecimento dos Crustáceos do Rio de Janeiro. Catálogo dos Crustáceos da Baía de Guanabara. Mems. Inst. Oswaldo Cruz 35: 137-151.

Ruffino, M.L.; M.D. Telles \& F.D’INCAO. 1994. Reproductive aspects of Chasmagnathus granulata Dana, 1851 (Decapoda, Grapsidae) in the Patos Lagoon estuary - Brazil. Nauplius, Rio Grande, 2: 43-52.

SAMPAiO, C.M.S. \& J. FAusto-Filho. 1984. Considerações sobre a bioecologia dos crustáceos decápodos da Enseada do Mucuripe (Fortaleza, Ceará, Brasil). Arq. Ci. Mar 23: 11-24.

ScotTo, L.E. 1979. Larval development of the cuban stone crab, Menippe nodifrons

(Brachyura, Xanthidae), under laboratory conditions with notes on the status of the family Menippidae. Fish. Bull. 77 (2): 359-386.

STUCK, K.C. \& H.M. PERRY. 1992. Life history characteristics of Menippe adina in Mississippi coastal waters. Fla Mar. Res. Publ. 50: 82-98.

Sullivan, J.R. 1979. The stone crab, Menippe mercenaria, in the southwest Florida fishery. Fla Mar. Res. Publ. 36: 1-37.

Vazoller, A.E.A.M. 1981. Manual de métodos para estudos biológicos de populações de peixes; reprodução e crescimento. Brasília, $\mathrm{CNPq}$, Programa Nacional de Zoologia, 108p.

WILBER, D.H. 1989. Reproductive biology and distribution of stone crabs (Xanthidae, Menippe) in the hybrid zone on the northeastern Gulf of Mexico. Mar. Ecol. Prog. Ser. 52: 235-244.

1992. Observations on the distribution and mating patterns of adult stone crabs (Genus Menippe) on the Northern Gulf Coast of Florida. Fla Mar. Res. Publ. 50: 10-16. 